\title{
Different aetiologies of Type 2 (non-insulin-dependent) diabetes mellitus in obese and non-obese subjects
}

\author{
P. Arner ${ }^{1}$, T.Pollare ${ }^{2}$ and H.Lithell ${ }^{2}$ \\ ${ }^{1}$ Department of Medicine, Huddinge Hospital, Karolinska Institute, Stockholm and \\ ${ }^{2}$ Department of Geriatrics, Kungsgärdets Hospital, Uppsala University, Uppsala, Sweden
}

Summary. Insulin responses to intravenous glucose infusion and glucose utilization during hyperinsulinaemic euglycaemic clamp were determined in a large homogeneous group of 65-year-old male subjects. Twenty-eight had untreated Type 2 (non-insulin-dependent) diabetes mellitus and the remaining 44 control subjects had a normal glucose tolerance. Diabetic patients with abdominal obesity displayed peripheral insulin resistance in combination with de- fective insulin secretion, whereas non-obese diabetic patients showed only a secretory defect. Thus, Type 2 diabetes in obese and non-obese elderly male subjects may take two forms where the cause of hyperglycaemia differs.

Key words: Insulin, glucose, obesity, glucose disposal, insulin secretion.
Insulin resistance is a common feature of many physiological and pathophysiological states [1]. Peripheral resistance appears to have a greater impact on glucose homeostasis than does resistance in the liver because the periphery (i.e. skeletal muscle) handles the major part of insulin-induced glucose disposal $[2,3]$. It is often believed that insulin resistance is the major cause of glucose intolerance in Type 2 (non-insulin-dependent) diabetes mellitus; the resistance cannot be overcome by an increased production of insulin by the Beta cell [1-6]. Most Type 2 diabetic patients are obese and obese normoglycaemic subjects are also insulin resistant. However, obese subjects have a hyperinsulinaemia that compensates for insulin resistance and results in normal or only a slightly impaired glucose tolerance. When the resistance becomes worse in obesity and/or the Beta cells cannot produce the amount of hormone necessary to compensate for insulin resistance, hyperglycaemia develops [6].

The proposed model for the pathogenesis of Type 2 diabetes is mainly based on studies of obese subjects. Although some studies have found insulin resistance in nonobese patients with Type 2 diabetes [7-10] it is not yet clear whether this type of diabetes in non-obese patients is due to impaired insulin secretion, to insulin resistance or to both. This question is addressed in the present study which was performed on a large homogeneous group of 65 -year-old men undergoing health screening. The insulin response to intravenous glucose injection and glucose utilization during a hyperinsulinaemic euglycaemic clamp was determined in 28 asymptomatic untreated Type 2 diabetic patients of whom 16 were obese and the remainder non-obese. The results were compared with those in 44 matched healthy control subjects with normal intravenous glucose tolerance.

\section{Subjects and methods}

\section{Subjects}

All the subjects were males between $60-70$ years of age. They participated in a health screening study in Uppsala, a medium-sized town in Sweden [11]. The subjects were healthy and not taking any medication, except for moderate obesity (body mass index $>25$ ) and Type 2 diabetes in affected individuals. The subjects were divided into four groups: 21 non-obese and 23 obese control subjects with normal intravenous glucose tolerance [12], and 12 non-obese and 16 obese diabetic subjects. Diabetes, which was asymptomatic, was diagnosed during the health-screening procedure. The urine of the diabetic subjects was free from glucose and ketones. Diabetes was defined as fasting blood glucose above $7.0 \mathrm{mmol} / \mathrm{l}$ and a $\mathrm{k}$-value below 0.9 . After the study the diabetic patients were treated with diet alone or in combination with sulphonylurea. During a follow-up period of at least one year none of these patients developed secondary sulphonylurea failure. They all followed a similar diet $(10.5 \mathrm{~mJ} / 24 \mathrm{~h})$ that consisted of $35 \%$ fat, $48 \%$ carbohydrates, $15 \%$ protein and $2 \%$ alcohol, as judged by a dietary history [11]. After an overnight fast, each subject underwent on separate occasions a metabolic investigation and an insulin sensitivity test. The subjects were instructed to adhere to a diet rich in carbohydrates (at least $250 \mathrm{~g}$ daily) and to abstain from hard physical exercise or inactivity for at 
Table 1. Clinical data of the groups studied

\begin{tabular}{lclllll}
\hline Group & $n$ & $\begin{array}{l}\text { Age } \\
\text { (years) }\end{array}$ & $\begin{array}{l}\mathrm{BMI} \\
\left(\mathrm{kg} / \mathrm{m}^{2}\right)\end{array}$ & W/H & $\begin{array}{l}\text { FBG } \\
(\mathrm{mmol} / \mathrm{l})\end{array}$ & $\begin{array}{l}\text { IVGT } \\
(\% / \mathrm{min})\end{array}$ \\
\hline $\begin{array}{l}\text { Control } \\
\text { Obese }\end{array}$ & 21 & $65 \pm 1$ & $23.6 \pm 0.2$ & $0.86 \pm 0.01$ & $4.7 \pm 0.1$ & $1.33 \pm 0.08$ \\
$\begin{array}{l}\text { Diabetes, } \\
\text { non-obese }\end{array}$ & 12 & $66 \pm 1$ & $29.5 \pm 0.6^{\mathrm{a}}$ & $0.95 \pm 0.01^{\mathrm{a}}$ & $5.0 \pm 0.1^{\mathrm{b}}$ & $1.38 \pm 0.09^{\mathrm{b}}$ \\
$\begin{array}{l}\text { Diabetes, } \\
\text { obese }\end{array}$ & 16 & $63 \pm 1$ & $31.3 \pm 1.0^{\mathrm{a}}$ & $0.97 \pm 0.01^{\mathrm{a}}$ & $9.3 \pm 0.8^{\mathrm{a}}$ & $0.47 \pm 0.03^{\mathrm{a}}$ \\
\hline
\end{tabular}

Mean \pm SEM. $n=$ number of subjects. $B M I=$ body mass index. $\mathrm{W} / \mathrm{H}=$ waist/hip ratio. $\mathrm{FBG}=$ fasting blood glucose. IVGT $=$ intravenous glucose tolerance. ${ }^{\mathrm{a}} p<0.001$ vs control, ${ }^{\mathrm{b}} p<0.001$ for obese vs diabetes obese

Table 2. Circulating insulin levels before and after intravenous glucose infusion

\begin{tabular}{lrlll}
\hline & Control & Obese & $\begin{array}{l}\text { Diabetes, } \\
\text { non-obese }\end{array}$ & $\begin{array}{l}\text { Diabetes, } \\
\text { obese }\end{array}$ \\
\hline Fasting & $5.7 \pm 1.0$ & $12.2 \pm 1.4^{\mathrm{b}}$ & $7.7 \pm 1.6$ & $17.1 \pm 2.3^{\mathrm{b}}$ \\
$\begin{array}{l}\text { Peak } \\
\begin{array}{l}\text { Peak-minus } \\
\text { fasting }\end{array}\end{array}$ & $54.0 \pm 6.0$ & $76.1 \pm 9.0^{\mathrm{a}, \mathrm{c}}$ & $9.6 \pm 1.8^{\mathrm{b}}$ & $23.9 \pm 3.6^{\mathrm{b}}$ \\
\hline
\end{tabular}

mU/, mean \pm SEM. ${ }^{a} p<0.05$ vs control, ${ }^{b} p<0.001$ vs control, ${ }^{c} p<0.001$ for obese vs diabetes obese

Table 3. Insulin sensitivity studies

\begin{tabular}{lllll}
\hline & Control & Obese & $\begin{array}{l}\text { Diabetes, } \\
\text { non-obese }\end{array}$ & $\begin{array}{l}\text { Diabetes, } \\
\text { obese }\end{array}$ \\
\hline $\begin{array}{l}\text { Insulin, } \mathrm{mU} / 1 \\
\mathrm{M}, \mathrm{mg} \text { glucose }\end{array}$ & $96 \pm 3$ & $105 \pm 5$ & $97 \pm 6$ & $111 \pm 5^{\mathrm{a}}$ \\
$\mathrm{kg}^{-1} \cdot \mathrm{min}^{-1}$ & $7.6 \pm 0.4$ & $5.4 \pm 0.3^{\mathrm{b}, \mathrm{c}}$ & $6.8 \pm 0.4$ & $2.6 \pm 0.2^{\mathrm{b}}$ \\
$\mathrm{M} / \mathrm{I} \times 100$ & $8.4 \pm 0.5$ & $5.5 \pm 0.5^{\mathrm{b}, \mathrm{c}}$ & $7.5 \pm 0.7$ & $2.5 \pm 0.3^{\mathrm{b}}$ \\
\hline
\end{tabular}

Mean \pm SEM. $M=$ rate of glucose infusion. $M / I=M$ value divided by the insulin value during clamp. ${ }^{\mathrm{a}} p<0.05$ vs control, ${ }^{\mathrm{b}} p<0.001 \mathrm{vs}$ control, ${ }^{c} p<0.001$ for obese vs diabetes obese

least five days before each of the two investigations. Each subject was questioned regarding heredity for diabetes and hypertension among first-degree relatives. The study was approved by the Ethics Committee of Uppsala University.

\section{Metabolic investigation}

Waist-to-hip ratio and body mass index were calculated and the metabolic investigation was conducted, as described in detail recently [13]. First, fasting venous blood samples were drawn for the determination of the plasma levels of glucose and insulin. Then the insulin response to an intravenous glucose load was investigated. The disappearance rate of glucose (k-value) was calculated [13] and the peak insulin response to intravenous glucose [12] which reflects the firstphase insulin secretory response [14] was defined as the mean of the values obtained at 2, 4 and 6 min after glucose injection.

\section{Insulin sensitivity studies}

The euglycaemic hyperinsulinaemic clamp technique was used to estimate in vivo sensitivity to insulin. The protocol has been described in detail [13]. Insulin was infused as an initial priming dose for the first $10 \mathrm{~min}$ and then as a continuous infusion for $110 \mathrm{~min}$ at the rate of $56 \mathrm{mU} / \mathrm{m}^{2}$ in all subjects, which resulted in a plasma insulin concentration in the range of 69-145 $\mathrm{mU} / \mathrm{l}$. The target plasma glucose concentration during the clamp procedure was $5.3 \mathrm{mmol} / \mathrm{l}$, which was reached within $60 \mathrm{~min}$ of the start of the insulin infusion in each subject. Steady-state plasma glucose concentration was determined and the M-value (rate of glucose infusion during the last hour of the clamp) was calculated. An insulin sensitivity index (M/I) was obtained by dividing the M-value (mg glucose taken up $\mathrm{kg}$ body weight ${ }^{-1} \cdot \mathrm{min}^{-1}$ ) by the steady-state insulin value (mU/1) during the last hour of the clamp $[15,16]$.

\section{Statistical analysis}

The values are mean \pm SEM. Values were compared statistically using the Student's unpaired $t$-test, analysis of variance of repeated measures (Tukey's test) and Fisher's exact test.

\section{Results}

The clinical data of the four groups are presented in Table 1 . The obese diabetic and non-diabetic groups had similar moderate degrees of obesity. The waist/hip ratio indicated that the obesity was of the abdominal type in both of these groups. The results concerning fasting blood glucose and intravenous glucose tolerance show that glucose homeostasis was slightly worse in obese diabetic than in non-obese diabetic patients $(p<0.01)$.

The data concerning insulin calculations are given in Table 2. As expected the obese diabetic subjects and obese non-diabetic subjects had fasting hyperinsulinaemia. However, the insulin response to intravenous glucose was increased in the obese non-diabetic and decreased in the obese diabetic subjects. The latter was true for peak and peak-minus fasting insulin. Non-obese diabetic subjects showed no change in fasting insulin, but their peak and peak-minus fasting insulin levels were markedly depressed. The fasting insulin level was more than two times higher in obese as compared to non-obese diabetic patients $(p<0.01)$.

As regards peripheral insulin insensitivity, the results of this investigation are summarized in Table 3 . The obese control and obese diabetic subjects had decreased $\mathrm{M}$ and $\mathrm{M} / \mathrm{I}$ values; this decrease was more marked in the latter group. In the non-obese diabetic subjects, however, neither $\mathrm{M}$ nor $\mathrm{M} / \mathrm{I}$ was different from the control group. The insulin levels during the clamp were significantly higher in the diabetic obese group than in the other three groups. During the last hour of the clamp the plasma glucose value was $5.32 \pm 0.02 \mathrm{mmol} / \mathrm{l}$ in the control group. Almost identical glucose values were obtained in the other three groups (data not shown).

In Tables 1-3 we used the Student's $t$-test for statistical comparison. However, similar results were obtained when analysis of variance was used as the statistical method.

In order to evaluate the individual values which represented insulin sensitivity and peak insulin secretory response to intravenous glucose a normal range of values was constructed for peak minus fasting insulin concentration and for M/I. One standard deviation above and below the mean value for the non-obese control group was used 

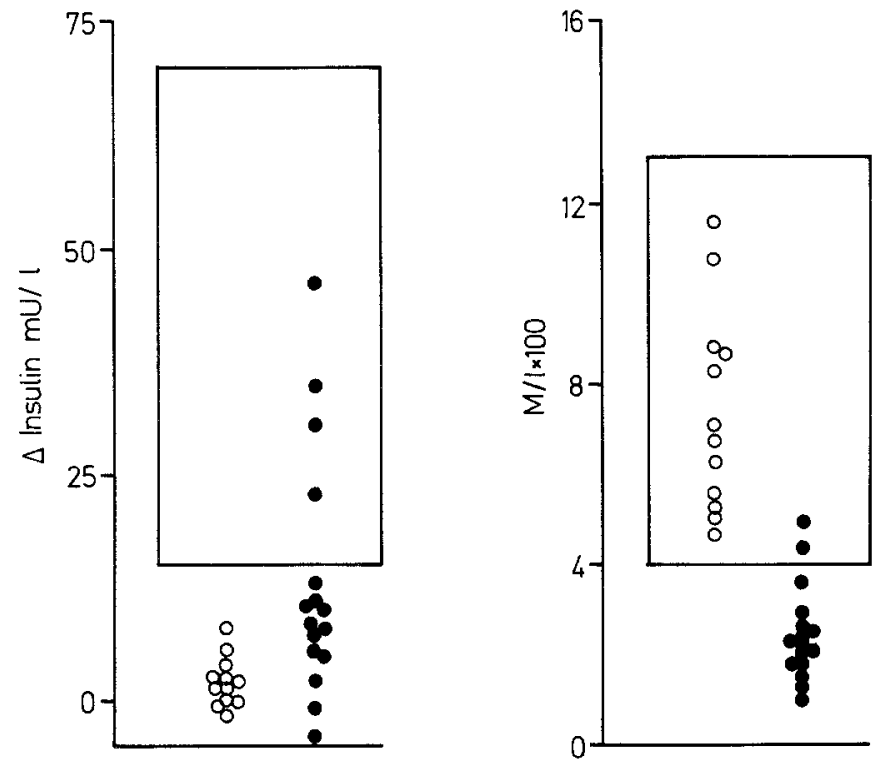

Fig. 1. Individual values for insulin secretion and insulin sensitivity in diabetes. $\Delta$ insulin $=$ peak plasma insulin after intravenous glucose load minus fasting plasma insulin. $\mathrm{M} / \mathrm{I}=$ insulin sensitivity index. $=$ obese diabetic subjects. $O=$ non-obese diabetic subjects. Rectangular areas indicate the normal range

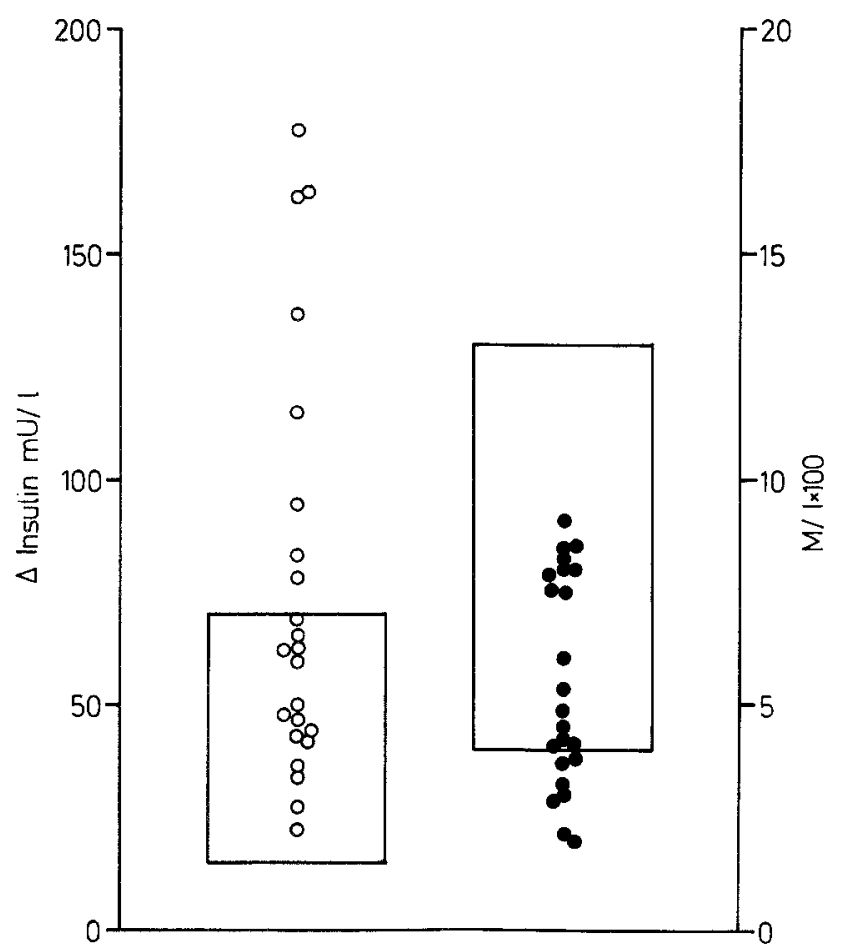

Fig. 2. Individual values for insulin secretion $(O)$ and insulin sensitivity ( ) in obese non-diabetic subjects. See legend to Figure 1 for further details

as the normal range (i. e. a $95 \%$ confidence interval), since the values for peak minus fasting insulin concentration and $M / I$ were normally distributed in the non-obese group with normal glucose tolerance. The individual values for diabetic subjects are depicted in Figure 1. As regards circulating insulin, the obese diabetic subjects were a heterogeneous group: three of whom had values within the

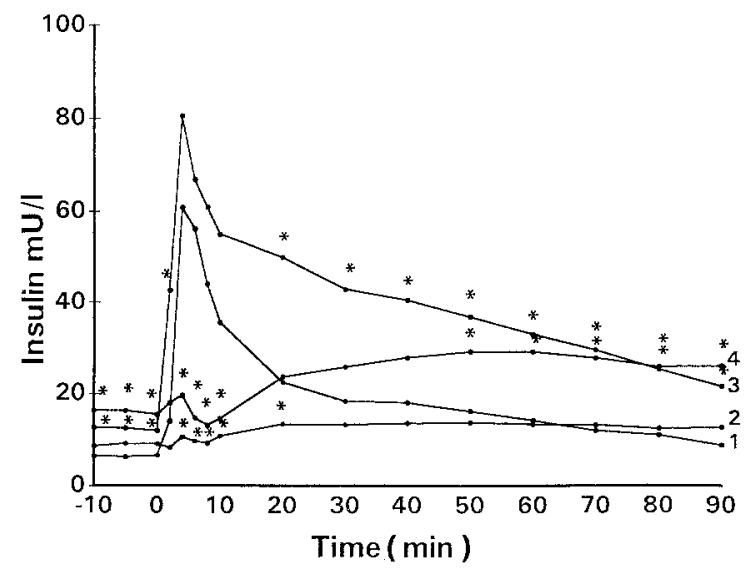

Fig.3. Insulin secretory response in control subjects (1), non-obese diabetic subjects (2), obese non-diabetic subjects (3) and obese diabetic subjects (4). Plasma insulin was determined before and after an intravenous glucose load at the time points indicated in the figure. Values obtained with the study groups were compared with control values using analysis of variance. Mean curves for the different groups are depicted. An asterisk above each curve indicates $p<0.01$ (or better) when compared with control curve

normal range and the remaining 13 had decreased values. $\mathrm{M} / \mathrm{I}$ also showed some heterogeneity in the obese diabetic group. Two subjects had normal values and the remainder had decreased values. The non-obese diabetic subjects appeared to be a highly homogeneous group. All subjects had insulin secretory values far below the normal range and all the $\mathrm{M} / \mathrm{I}$ values were evenly distributed within the normal range. The individual values for obese nondiabetic subjects are depicted in Figure 2. Seven had decreased $\mathrm{M} / \mathrm{I}$ and eight had increased insulin secretory values. Six of the latter subjects belonged to the group with low $\mathrm{M} / \mathrm{I}$.

First- and second-phase insulin secretory response to intravenous glucose is shown in Figure 3. Both phases were significantly decreased in non-obese diabetic patients and significantly increased in obese non-diabetic subjects. In obese diabetic patients the first-phase response was significantly decreased but the second phase response was somewhat enhanced.

Diabetic patients tended to have different heredity for diabetes and hypertension as compared to non-diabetic subjects. A heredity for diabetes was found in $47 \%$ of the diabetic patients and in $25 \%$ of the non-diabetic subjects ( $p=0.07$ using Fisher's exact test). Corresponding values regarding heredity for hypertension were $10 \%$ and $25 \%$ $(p=0.09)$.

\section{Discussion}

In this study we investigated insulin secretion and peripheral insulin sensitivity in a very homogeneous population of 65-year-old men, all living in the same area and having similar dietary habits. In men with abdominal obesity and normal glucose tolerance, peripheral insulin resistance in combination with a compensatory increase in insulin secretion was observed. Abdominal obese Type 2 diabetic 
males had a more marked peripheral resistance and decreased insulin secretory response to glucose. These data concerning obese non-diabetic and diabetic subjects are in consonance with numerous previous investigations which have been reviewed in detail [1-6]. In non-obese hyperglycaemic subjects, however, there was no evidence of peripheral insulin resistance, which is a new finding. All of the latter subjects had only a marked secretory defect involving both the first- and second-phase response. The present findings with fasting plasma insulin and glucose are also evidence of a greater insulin resistance in obese as compared to non-obese diabetic patients.

Our data concerning insulin resistance in non-obese diabetic subjects are at odds with previous results, showing significant peripheral insulin resistance in non-insulindependent diabetic subjects with normal body weight [710]. There are, however, several important differences regarding patient characteristics between our and previous investigations. Both female and male subjects were included in the previous study groups [7-10] and the diabetic patients were $10-15$ years younger than our patients [7-10]. In addition, the control subjects were 1020 years younger than the diabetic subjects in three of the earlier studies $[7,8,10]$. The aging process per se appears to have its own deleterious effect on peripheral insulin sensitivity [17]. Finally, diabetes was not newly diagnosed in the previous reports and most patients had received antidiabetic therapy for several years [7-10]. Thus, several factors may explain the discrepancy between present and previous results. Furthermore, insulin secretion was not measured in the earlier investigations [7-10].

It should be noted that only peripheral insulin resistance was evaluated in this study. Quantitatively, however, peripheral tissues (i.e. skeletal muscle) are the major tissues responsible for decreased in vivo insulin action in insulin-resistant states $[2,3]$. Under the present hyperinsulinaemic euglycaemic clamp conditions, endogenous glucose production by the liver is completely suppressed, even in the most resistant obese diabetic subjects $[15,16]$. Thus, it is possible that our non-obese diabetic patients may be resistant to insulin in the liver, such resistance is revealed at insulin levels lower than those obtained during the clamp investigation. On the other hand, the concentration of insulin (67-145 mU/1) obtained in the present study is relevant to the peripheral effects of the hormone, since such insulin levels can be reached in normal subjects in connection with a glucose load. It is, however, unlikely that there is a right word shift of the dose response curve in lean diabetic patients due to decreased insulin sensitivity in skeletal muscle, since we recently found normal insulin receptor binding and normal sensitivity of insulin receptor tyrosine kinase activity in skeletal muscle of this group of patients [18].

Because of ethical reasons insulin secretion in man can only be determined indirectly. We used plasma insulin response to an intravenous glucose load because it is simple, reproduceable and discriminates between a first-phase peak insulin response and a second-phase response; the former response correlates well with intravenous glucose tolerance [14]. Non-obese diabetic subjects had decreased first- and second-phase insulin secretion, whereas in obese diabetic patients only the first-phase insulin response was decreased, the second-phase response was slightly enhanced. The meaning of the latter is unclear at present. First-phase response may be more important for glucose tolerance than second-phase response $[14,15]$. In addition, pro-insulin which cross-reacts with insulin antibodies, may to an unknown extent contribute to the findings. However, there is a disproportionate increase in pro-insulin secretion in Type 2 diabetic patients [19]. Thus, the presently observed defect in first-phase insulin secretion in the two diabetes groups is, if anything, underestimated.

It is clear that Type 2 diabetes is not a single disorder but is rather a syndrome of great heterogeniety $[20,21]$. Rare cases of diabetes where an abnormal insulin molecular or incomplete conversion of pro-insulin to insulin is the underlying cause of the disease have been reported [22]. Mutations in the insulin receptor gene leading to insulin resistance, and consequently to diabetes, have also been described recently [23, 24]. When diabetes is associated with obesity, the disease usually seems to be caused by insulin resistance plus an impaired ability of the pancreas to compensate for the resistance. The present data suggest that non-obese diabetic elderly male subjects form another subgroup of the disease where peripheral insulin action is normal and the insulin secretory defect is the major cause of the disease. Whether such patients are resistant at the level of the liver remains to be determined. In addition, the present results do not rule out the possibility that peripheral insulin resistance is present in young or female non-obese subjects with Type 2 diabetes.

Acknowledgements. We thank L. Berglund for statistical advice. This study was supported by grants from the Medical Research Council, Karolinska Institute, Swedish Diabetes Association and Stohne, Osterman, Nordic Insulin and Aage Louise Hansen Foundations.

\section{References}

1. Reaven GM (1988) Role of insulin resistance in human disease. Diabetes 37: 1595-1607

2. Beck-Nielsen H (1989) Insulin resistance in skeletal muscles of patients with diabetes mellitus. Diab Metab Rev 5: 487-493

3. Bogardus C (1989) Perspective: does insulin resistance primarily affect skeletal muscle? Diab Metab Rev 5: 527-528

4. Gerich JE (1988) Role of insulin resistance in the pathogenesis of type 2 (non-insulin-dependent) diabetes mellitus. Baillières Clin Endocrinol Metab 2: 307-326

5. Taylor R, Agius L (1988) The biochemistry of diabetes. Biochem J 250:625-640

6. Pedersen P (1989) The impact of obesity on the pathogenesis of non-insulin-dependent diabetes mellitus: a review of current hypothesis. Diab Metab Rev 5: 505-509

7. Ginsberg H, Kimmerling G, Olefsky JM, Reaven GM (1975) Demonstration of insulin resistance in untreated adult onset diabetic subjects with fasting hyperglycemia. J Clin Invest 155: 454-461

8. Kolterman OG, Gray RS, Griffin J, Burstein P, Insel J, Scarlett JA, Olefsky JM (1981) Receptor and post-receptor defects contribute to the insulin resistance in non-insulin-dependent diabetes mellitus. J Clin Invest 68: 957-969

9. De Fronzo RA, Simonson D, Ferrannini E (1982) Hepatic peripheral insulin resistance: a common feature of Type 2 (non-in- 
sulin-dependent) and Type 1 (insulin-dependent) diabetes mellitus. Diabetologia 23: 313--319

10. De Fronzo RA, Gunnarsson R, Björkman O, Olsson M, Wahren $\mathrm{J}$ (1985) Effects of insulin on peripheral and splanchnic glucose metabolism in non-insulin dependent (Type I) diabetes mellitus. J Clin Invest 76: 149-155

11. Bolinder J, Lithell H, Skarfors E, Arner P (1986) Effects of obesity, hyperinsulinemia and glucose intolerance on insulin action in adipose tissue of sixty-year old men. Diabetes 35:282-290

12. Ikkos D, Luft R (1957) On the intravenous glucose tolerance test. Acta Endocrinol (Copenh) 25:312-334

13. Pollare T, Lithell H, Selinus I, Berne C (1988) Application of prazosin is associated with an increase of insulin sensitivity in obese patients with hypertension. Diabetologia 31:415-420

14. Thorell JI, Nosslin B, Sterky G (1973) Estimation of the early insulin response to intravenous glucose injection. $\mathrm{J}$ Lab Clin Med 82: 101-110

15. Bergman RN, Finegood DT, Ader M (1985) Assessment of insulin sensitivity in vivo. Endocrin Rev 6:45-86

16. Livingston J, Pollare T, Lithell H, Arner P (1988) Characterization of insulin-like growth factor I receptor in skeletal muscles of normal and insulin resistant subjects. Diabetologia 31: 871-877

17. De Fronzo RA (1981) Glucose intolerance and aging. Diabetes Care 4: 493-501

18. Arner P, Pollare T, Lithell H, Livingston JN (1987) Defective insulin receptor tyrosine kinase in human skeletal muscle in obesity and Type 2 (non-insulin-dependent) diabetes mellitus. Diabetologia 30: $437-440$
19. Porte D Jr., Kahn SE (1989) Hyperproinsulinemia and amyloid in IDDM. Clues to etiology of islet beta-cells dysfunction? Diabetes 38: 1333-1336

20. Efendic S, Luft R, Wajngot A (1984) Aspects of the pathogenesis of type II diabetes. Endocr Rev 5: 395-410

21. Zimmet P (1989) Non-insulin-dependent (type 2) diabetes mellitus: does it really exist? Diab Med 6: 728-735

22. Pershadsingh HH, Christensen RL, McDonald JM (1986) Cellular mechanisms of insulin action: implications for insulin resistance and type II diabetes mellitus. Clin Chem 32: B19-B27

23. Yoshimasa Y, Seino S, Whittaker J, Kakehi T, Kosaki A, Kuzuya H, Imura H, Bell GI, Steiner DF (1988) Insulin-resistant diabetes due to a point mutation that prevents insulin proreceptor processing. Science 240: 784-787

24. Kadowaki T, Bevins CL, Cama A, Ojamaa K, Marcus-Sammels B, Kadowaki H, Beitz L, McKeou C, Taylor SI (1988) Two mutant alleles of the insulin receptor gene in a patient with extreme insulin resistance. Science 240: 787-790

Received: 8 June 1990

and in revised form: 20 February 1991

\section{Dr. P. Arner}

Department of Medicine

Huddinge Hospital

S-141 86 Huddinge

Sweden 